\title{
Geogenomics - integrating geology and phylogenetics to unravel the evolutionary history of Earth and its biota
}

Sherilyn C. Fritz ${ }^{1}$ and Paul A. Baker ${ }^{2}$

\begin{abstract}
Phylogenetic data have great potential for testing hypotheses about the nature and timing of geological and climatic events. We provide examples of how phylogenies have been used to constrain environmental history and propose the broader use of this approach.
\end{abstract}

Phylogeography investigates the evolutionary history (phylogeny) and spatial structure of groups of organisms (Avise 2000), often linking the history of biological lineages to Earth history. In this approach, similarities and differences in the genetic composition of various contemporary species or taxonomic groups are used to establish evolutionary relationships (phylogenetics), and this evolutionary history is time calibrated using dated fossils and molecular clock calculations. In phylogeography, the time-calibrated history of descent is subsequently related to coincident geologic events, such as mountain uplift, river formation and migration, glaciation, or climate change. These events may have created barriers to dispersal and fragmented populations (vicariance) or alternatively generated corridors for migration that increased gene flow among populations. The explosive development of genetic sequencing technologies has resulted in a proliferation of recent phylogeographic studies that reconstruct the evolution of life and link the history of diversification and speciation to the evolution of the environment.

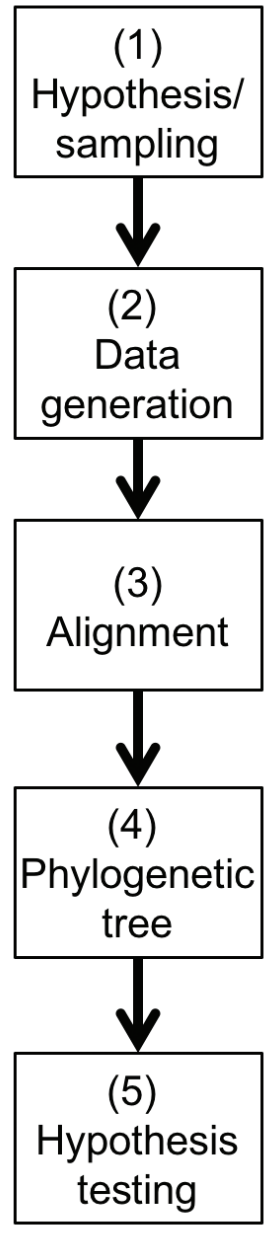

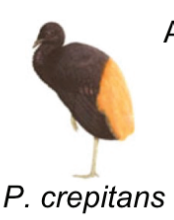

Amazon River
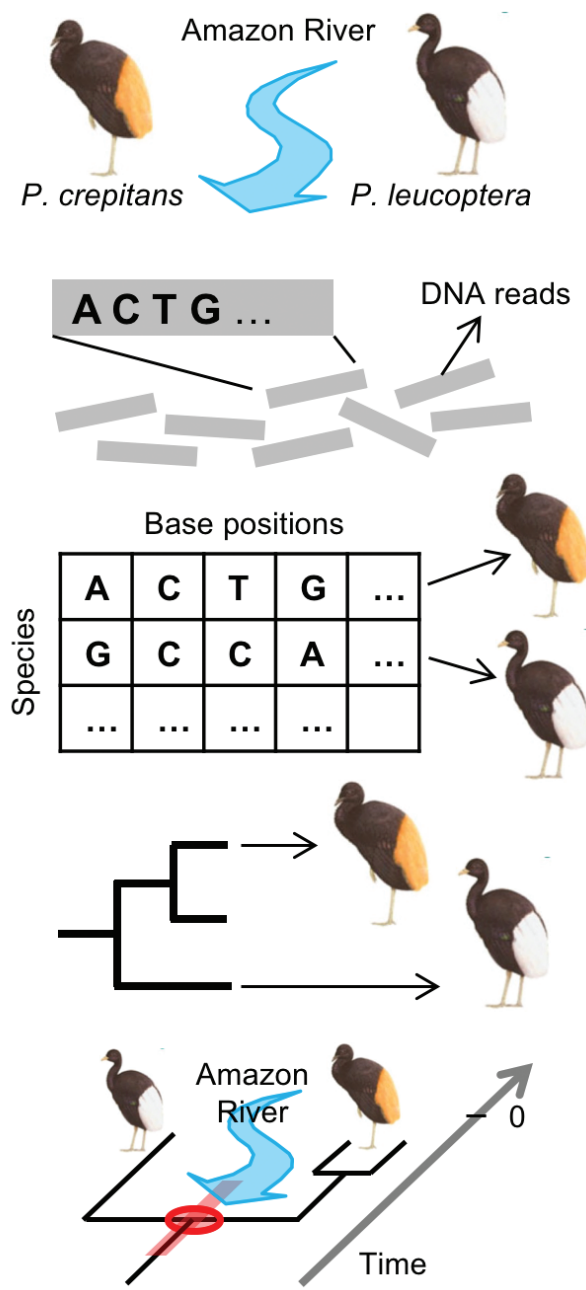

Figure 1: A schematic diagram showing how phylogenetic data on modern flightless bird populations has been used to test the timing of the formation of a river system. The phylogenetic tree defines the evolutionary relationship between bird species that occupy different river drainages in the Amazon, and the dated branching points in the phylogeny suggests events that split populations and led to genetic isolation and subsequent speciation. From Baker et al. 2014, reprinted with permission from Elsevier.
This process of studying the role of geological and climatic processes in the evolution of ancient lineages also has been called "phylogeology" (Acosta et al. 2014). Such studies rely on a well-constrained history of geological and climatic events.

Often, the nature and timing of geological events is not well constrained, and contrasting scenarios of various aspects of Earth history have been proposed in the literature. We suggest that, in some of these cases, the most common direction of study, relating phylogenetic divergences to geological events, can be inverted, such that timecalibrated phylogenetic trees can be used to inform environmental history. We call this new integrated discipline of testing geologic scenarios with genetic data "geogenomics" (Baker et al. 2014). Here, we summarize a few recent studies that use phylogenetic data to constrain geologic history. In presenting these examples, we hope to encourage additional geogenomic investigations and increased communication among evolutionary biologists and geologists.

\section{The evolution of riverine barriers}

A study by Ribas and colleagues (2013) of trumpeters, a group of flightless birds that exhibits a high degree of endemism, with different species occupying different drainage basins of the Amazon River system, first stimulated our interest in geogenomics and its potential for advancing understanding of Earth history (Baker et al. 2014). The timing of the development of the current transcontinental drainage pattern of the Amazon River is hotly debated, with estimates ranging from Miocene to Quaternary. Ribas and colleagues used a phylogenetic analysis of trumpeters to test different models of the geomorphic evolution of the river (Fig. 1). The analysis showed that diversification of trumpeters occurred relatively recently, between 3 and $0.5 \mathrm{Ma}$ (millions of years ago), consistent with the more recent (PlioPleistocene) estimate for the establishment of trans-continental drainage. Moreover, the pattern of divergence between one clade (a group of organisms with a common ancestor) and another was used at finer resolution to constrain the ages of several major Amazon tributaries. Thus, the phylogenetic data were used to generate a testable hypothesis of geomorphic evolution. 



Figure 2: (A) The genetic diversity (chloroplast DNA haplotypes) of white spruce populations across northern North America. High genetic diversity suggests population persistence for long periods, spanning back through glacial times. (B) Isolated spruce populations, similar in density to the refugial populations envisaged during intervals of North American glaciation. From Hu et al. 2009, reprinted with permission from the Ecological Society of America.

\section{The Great American Biotic Interchange}

For many years, the Great American Biotic Interchange (GABI) between North and South America (Marshall 1988) was thought to be driven by the closure of the Isthmus of Panama and the generation of a continuous corridor of land between the two continents, dated at about $3 \mathrm{Ma}$. Yet recent geological studies (Montes et al. 2015) suggest a much earlier age for the closure (15-13 Ma), a hypothesis that is being contested in the geologic literature (O'Dea et al. 2016). Bacon and colleagues (2015) used molecular divergence dates, coupled with fossil data, to evaluate the timing of dispersal and vicariance in several different groups of organisms. Their analysis suggested a dramatic increase in the number of terrestrial taxa migrating between the continents about $3 \mathrm{Ma}$, but it also indicated increased migration during two earlier periods of the last $23 \mathrm{Ma}$, consistent with an earlier date for a land-based connection between North and South America. Similarly, marine organisms showed divergence in genetic structure consistent with an earlier separation of eastern and western populations by an emergent land bridge.

The hypothesis of an earlier (Miocene) closure of the Isthmus of Panama also has raised the question of whether the $3 \mathrm{Ma}$ date for GABI derived from paleontological data is robust and also whether a different environmental event facilitated an increase in bi-directional exchange. One possibility is that faunal exchange was enabled by the expansion of savanna in the Central American corridor, caused by altered atmospheric circulation patterns associated with the onset of Northern Hemisphere glaciation. This hypothesis was proposed decades ago by several vertebrate paleontologists who first studied GABI, because many of the mammals involved in the exchange are adapted to savanna (Webb 1978). Bacon and colleagues (2016) conducted a subsequent phylogenetic analysis of mammals involved in GABI and calculated that the majority of changes in genetic structure between the continents occurred between 4 and $3 \mathrm{Ma}$. While this analysis does not address the nature of the environmental trigger, it does confirm paleontological estimates of the timing of major biotic exchange.

\section{Glacial refugia}

Molecular genetic studies have revolutionized our understanding of the dynamics of plant populations following the retreat of continental ice sheets and montane glaciers at the end of the Pleistocene. In the Northern Hemisphere, paleoecological studies have used transects of pollen data to establish rates of migration and range expansion of tree populations that were thought to have survived glacial intervals in regions to the south and then migrated northward as the ice sheet retreated and climate warmed (Davis and Shaw 2001). More recently, however, population genetic studies of northern tree populations (Hu et al. 2009) have suggested that some species, such as white spruce, survived in refugia as small populations in areas adjacent to the ice sheet and subsequently expanded from these local areas to establish their current biogeographic distribution (Fig. 2). These new data have significant implications for calculations of potential tree dispersal rates and evaluating biological resilience to climate change. Early pollen analyses from Patagonia (Markgraf 1993) proposed that southern beech, Nothofagus, survived during glacial times in refugia on the now submerged coastal lowlands, rather than migrating long distances from the mid-latitudes, but this conclusion was controversial when originally proposed. Yet recent population genetic data (Premoli et al. 2010) indicate that species of Nothofagus persisted during glacial intervals both in ice-free regions of Patagonia, as well as in periglacial areas. Thus, a growing body of phylogenetic data indicates that in many regions small refugial tree populations persisted on the landscape through intervals of unfavorable climate.

\section{Prospects for the future}

The examples provided above suggest the potential for phylogenetic reconstructions to be used in generating or testing hypotheses about geological and environmental history. Doing so necessitates a well-developed understanding of the assumptions and uncertainties involved in phylogenetic reconstruction, just as biogeographic calibration of phylogenies based on geological data requires explicit accommodation of dating errors and an understanding of the mode and rate of the geological processes involved ( $\mathrm{De}$ Baets et al. 2016). This need for a bi-directional flow of information suggests the value of expanded collaboration between geologists and evolutionary biologists in exploring the linkages between the evolution of life and the physical environment, and in furthering our understanding of the vital linkages between the biosphere and geosphere.

\section{AFFILIATIONS}

'Department of Earth and Atmospheric Sciences, University of Nebraska - Lincoln, USA

2Earth \& Ocean Sciences Division, Duke University, Durham, USA

\section{CONTACT}

Sherilyn Fritz: sfritz2@unl.edu

\section{REFERENCES}

Acosta MC et al. (2014) Geobiology 12: 497-510 Avise JC (2000) Phylogeography: The History and Formation of Species. Harvard University Press, $464 \mathrm{pp}$

Bacon CD et al. (2015) PNAS 112: 6110-6115

Bacon CD et al. (2016) Geol Soc Am Bull 44: 375-378

Baker PA et al. (2014) Earth Sci Rev 135: 38-47

Davis MB, Shaw RS (2001) Science 292: 673-679

De Baets K et al. (2016) Phil Trans R Soc B 371: 20160098

Hu FS et al. (2009) Front Ecol Evol 7: 371-379

Markgraf V (1993) Palaeogeog Palaeoclimatol Palaeoecol 102: 53-68

Marshall LG (1988) Am Sci 76: 380-388

Montes C et al. (2015) Science 348: 226-229

O'Dea A et al. (2016) Sci Adv 2: e1600883

Premoli A et al. (2010) Palaeogeog Palaeoclimatol Palaeoecol 298: 247-256

Ribas CC et al. (2013) Proc R Soc B 279: 681-689

Webb DA (1978) Ann Rev Ecol Systemat 9: 393-426 